
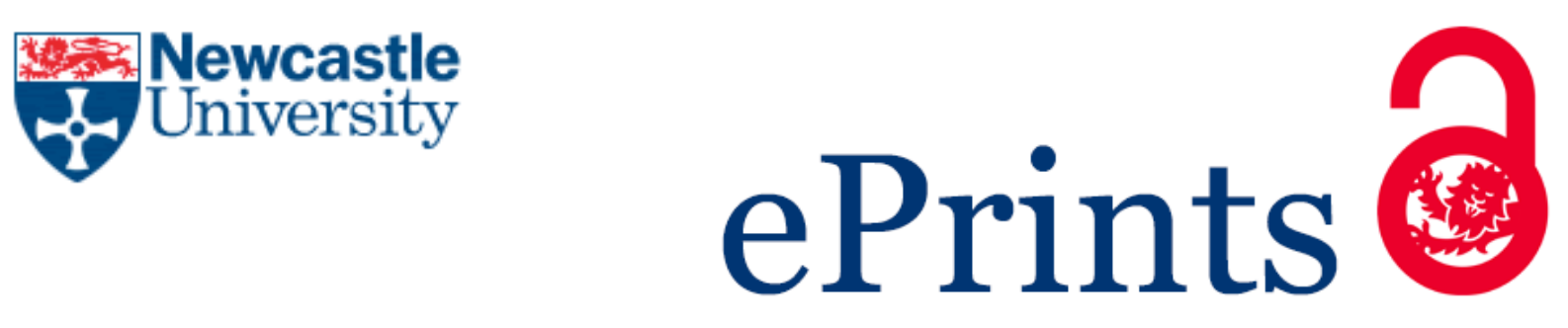

Pedersen OW.

Resilience in Environmental Law: Epistemic Limitations and the Role of

Participation.

In: Bridget M. Hutter, ed. Risk, Resilience, Inequality and Environmental Law. Edward Elgar, 2017, pp.49-63.

\title{
Copyright:
}

(C) Copyright 2017 Edward Elgar. This book chapter may be downloaded for personal use only. Any other use requires prior permission of the author and the publisher.

URL link to book:

http://www.e-elgar.com/shop/risk-resilience-inequality-and-environmental-law

Date deposited:

$06 / 06 / 2017$

Embargo release date:

28 January 2018 


\title{
Chapter 5
}

\section{Resilience in environmental law: epistemic limitations and the role of participation}

\author{
Ole W. Pedersen
}

\section{Resilience and environmental law}

When surveying the debates and literature on resilience, one is left with an acute sense that 'resilience' is to today's scholars and commentators what 'risk' was just a few years ago. Presently, debates have seemingly moved on from discussions on how best to manage and communicate risks to how best to develop resilient systems of management and governance. In this substitution of terminology, resilience is most commonly defined as a 'measure of persistence of systems and of their ability to absorb change and disturbance and still maintain the same relationship between populations or state variables' (Holling, 1973) and/or the 'reduced vulnerability to environmental risk experiences, the overcoming of a stress or adversity, or a relatively good outcome despite risk experiences' (Rutter, 2012). Unsurprisingly, up to this point, most of the resilience literature has focused on the extent to which the law and regulation reflect resilient practices, and implicitly, also whether the law thereby manages to facilitate resilience in the natural environment.

One thus encounters a significant amount of scholarly interest surrounding the perceived lack of resilience in environmental legal systems designed to facilitate environmental protection (Arnold and Gunderson, 2014; McDonald and Styles, 2014; Benson, 2015). Central to much of this literature, which admittedly focuses mainly on US law, is the implicit assumption that humans and the natural environment are faced with unprecedented and, to some extent, unforeseeable risks (though we will see that this argument inevitably poses some problems), which demand a redesign of existing methods and means of regulation. These risks include, most prominently, climate change impacts, biodiversity loss and species extinction (Ruhl, 2011; Craig, 2016). In this conceptualisation of certain serious risks, the concepts of tipping points and the emergence of the concept of the Anthropocene feature prominently, signalling a sense of urgency (Kim and Bosselman, 2013). In addition, a central theme running 
through much of this work is the appreciation that the subjects of much of environmental law (the natural environment, ecosystems, new technologies, and economies and markets in general), are highly complex yet adaptive systems which must be managed by an adaptive and flexible system of regulation. In other words, the law ought to reflect the subject which it regulates, taking the form of reverse mirror thesis (Tamanaha 2001).

Taken together, this serves as a platform upon which an argument for transforming the law is based. Thus, the most commonly advanced argument is typically that the existing environmental law is inherently ill-suited to dealing with these types of unprecedented risks; the law is seen as inflexible, maladaptive and as lacking responsiveness (Arnold and Gunderson, 2014). In response, the proponents of resilience thinking identify a series of characteristics which environmental law ought to possess. These include:

- Built-in review and monitoring mechanisms;

- Multiplicity of statutory objectives;

- The reconsideration of environmental decisions on an ongoing basis;

- Staged, tiered and/or conditional approvals of projects impacting on the environment;

- Sunset clauses in statutes, allowing for re-assessment of objectives (resulting in statutory provision being regularly and periodically reviewed);

- Enhanced public participation throughout the decision-making process.

These properties would ideally go some way towards remedying the critique levied against the present system of environmental law; primary amongst which is 'the expectation of administrative law that a decision-maker can make fully informed decisions up-front [which] is antithetical to adaptive management's underlying premise' (McDonald and Styles, 2014; Ruhl, 1997).

As noted above, much of the literature on resilience and environmental law has thus far focused on environmental law in the USA. In light of this, it seems relevant to ponder how well UK environmental law fares against the listed characteristics of resilience. The first point to make is that in so far as resilience is fostered by way of adaptability and flexibility there is reason to believe that today's environmental law fares rather well. One reason for this is the fact that present day environmental law in the UK represents a plethora of different statutory and administrative instruments, measures and approaches, covering a wide spectrum of regulatory methods (Macrory, 2014). Thus, while environmental law is often considered a paradigm embodiment of the regulatory command and control approach (which is per 
definition considered to be inflexible and rigid), the reality is that environmental law today is made up of a combination (admittedly, often a bewildering combination) of statutory and nonstatutory policy-based instruments. These include traditional instruments alongside a whole host of additional systems and means, providing for flexible implementation through incentivebased arrangements together with methods which allow the regulatory decisions to reflect local and present contexts. ${ }^{1}$ As a result, UK environmental law may well be deemed to embody features of resilience thinking.

Consider for example the system of regulation set up to regulate heavy industrial pollution in the UK found in the Environmental Permitting Regulations (England and Wales) 2016 and its underlying European Union rules which the UK government is obliged to implement as a matter of EU law. ${ }^{2}$ On the face of it, this is a paradigm example of command and control regulation. A violation of the Regulations' central requirement of a permit for those carrying out a regulated activity constitutes a criminal offence and thereby entails the risk of the imposition of a sanction This impression of a linear command and control system quickly fades, however, once the actual workings of the regulations are considered. Most importantly, the background against which specific standards are set by the Environment Agency for particular activities and facilities is through the so-called best available technique (BAT) norm which, as the name suggests, is not a one-size fit all standard applied across the board. ${ }^{3}$ Instead the BAT standard provides for a differentiated system of regulation, whereby different sectors and operators are subject to standards which are specifically drawn up with that sector in mind. Moreover, the manner in which specific BAT standards are developed further serves to highlight inherent flexibility in the system. BAT is not a static norm but is developed by reference to so-called background BAT Reference (BREF) documents which are drawn up through a technocratic yet participatory process (at EU level) where regulators, industry representatives, scientists and NGOs take part (Lange 2008). A significant downside of this flexible and technocratic process is, however, that it potentially affords a privileged position to certain interest and actors over others (Abbot and Lee, 2015). In this process, existing asymmetries in respect of inequality of involvement and participation are likely to be intensified. Nevertheless, this importantly results in a situation where the 'front-end' standard setting of the regulatory process does not necessarily reflect the ideas typically associated with

\footnotetext{
${ }^{1}$ Scotford and Robinson (2013), argue that to a large degree, parts of the environmental law is indistinguishable from politics).

${ }^{2}$ The Environmental Permitting (England and Wales) (Amendment) (England) Regulations 2015.

${ }^{3}$ This is the primary statutory agency in England, created in 1996, responsible for pollution and waste control.
} 
command and control systems. When turning to the 'back-end' of the regulatory process, it becomes equally evident that we are dealing with a system which exhibits significant amounts of flexibility and adaptiveness. This is particularly so when considering the fact that one underlying directive (EU Industrial Emissions Directive, 2010) does allow for local derogation from BAT standards both on account of the setting of stricter as well as less strict emission standards.

A further factor is the extension of the recently introduced civil sanctions regime to the permitting regulations in the context of enforcement. This is most notable in the use of enforcement undertakings, whereby the Environment Agency, instead of commencing criminal proceedings, may enter into a civil agreement with an operator who has committed an offence. One of the main reasons behind introducing this regime in general, and the enforcement undertakings in particular, was that these would allow for added flexibility and appreciation of individual circumstances in the regulatory process (Pedersen 2013a). This latter point partly serves to highlight the increased extent to which environmental regulators in the UK enjoy a great deal of discretion in the administration of the law (Fisher, Lange and Scotford, 2013, pp. 89-92). While there are of course downsides to this increase in discretion, from a resilience point of view, it serves to highlight how present day UK environmental law is not necessarily (if it ever was) a system of simple rigid statutory commands which are implemented and enforced in an unyielding fashion by the regulators (Hawkins, 1984). In other words, UK environmental law may well in fact already exhibit some of the flexibility and adaptability which the resilience critics of the law seek to implant in it. Importantly, however, in order to come to this conclusion on has to look beyond statutory framework and examine the manner in which the system works on the ground.

Linked to issue of flexibility is the fact that further potential for adaptability in the statutory framework is secured through the high frequency with which environmental lawmakers make use of secondary legislation (Scotford and Robinson, 2013). While this is not unique to environmental law, for various reasons, environmental law is particularly rich on secondary legislation to the extent that many of the main statutory regimes forming the backbone of UK environmental law are promulgated through secondary rather than primary legislation in the form of acts of Parliament. Though this naturally makes for a bewildering assortment of different regulations it has, from the point of view of the rule-maker, the significant advantage of allowing for flexibility as a result of the relative ease with which such secondary instruments are amended when the need arises. 
The properties of resilience associated with undertaking monitoring and reviewing of the law in light of factual developments is not just implicitly facilitated through the workings of a system based on secondary legislation, but is also found explicitly in parts of the law. This is most prominent in the Climate Change Act 2008 and its central emphasis on parliamentary oversight as a mechanism for its enforcement. Whereas this emphasis is significantly different from the move towards less formal systems of sanctioning found in the environmental permitting regulations, it nevertheless represents an example of the law's adaptability. The main reason for this is found in the obligations on the Secretary of the State to lay before Parliament yearly reports detailing the amount of UK emissions thereby allowing parliamentary oversight of the progress towards meeting the Act's overall obligations (s.16, Climate Change Act 2008). ${ }^{4}$ While Parliament would no doubt have been able to request such information anyway, the explicit obligation on the Secretary of State, signals the important emphasis which the Act attaches to continuous review and potential adaption in light of this.

In addition to these factors all approximating some form of flexibility and adaptability in environmental law, a feature worth recalling is the extent to which environmental law and regulation as a sub-discipline within parts of the administrative law is singled out for special treatment when it comes to the way in which environmental cases find their way to the courts. Though it is often (and rightly) pointed out that access to justice in environmental law is prohibitively expensive for many people, it does not disguise the fact that environmental cases before the courts benefit from favourable treatment (in terms of process not necessarily substance) when it comes legal standing and the extent to which applicants are able to seek protection from high costs. Much of this is owed to the 1998 Aarhus Convention ${ }^{5}$ and its emphasis in its 'third pillar' on access to justice. These obligations have slowly found their way into UK law to the extent that applicants in so-called Aarhus judicial review cases ultimately are exposed to a much lower cost level (and thereby risk) when it comes to bringing environmental cases to the courts. This potentially gives rise to a more robust and resilient body of law as it is less onerous for NGOs and members of the public to challenge decision-making procedures in the courts compared to other areas of law. It also means that decisions made by public authorities, like the Environment Agency, are perhaps subject to a higher degree of scrutiny by NGOs and members of the public when these relate to the environment e.g. $R$ (on

\footnotetext{
${ }^{4}$ HM Government <http://www.legislation.gov.uk/ukpga/2008/27/section/16>

${ }^{5}$ An international treaty adopted under the auspices of the United Nations which the UK has to comply and the first of its kind to explicitly provide for individual environmental rights.
} 
the application of ClientEarth) (Appellant) v. Secretary of Statefor the Environment, Food and Rural Affairs (Respondent).

In sum, what emerges from this brief overview of some of the central parts of and recent changes made to environmental law in the UK is a picture of a system which is not necessarily one lacking in characteristics of resilience. On the contrary, it seems that across a spectrum of environmental law (not necessarily in every instrument within the law), one encounters a high proportion of adaptable and potentially flexible instruments, reflecting features called for by those pursuing the argument of resilience. As a consequence, what emerges is perhaps a body of law which is in fact resilient in certain aspects though perhaps not in every single one.

\section{The ex-ante problem with 'designing' resilience}

In light of the analysis above one central question emerges. Notwithstanding that current environmental law shows some sign of being resilient, there is a strong emphasis within the literature on the need for an even more resilient body of law. Thus, it is worth pondering whether it is at all possible to deliberately instil resilience in the law as advocated in much of the literature (Arnold and Gunnderson, 2014; McDonald and Styles, 2014). Much of the resilience and adaptation literature answers this in the affirmative. In this, however, one encounters an acute sense of the proponents of resilience thinking having their cake and eating it. For example, many of the features which are identified as providing resilient features are not necessarily found in systems, be it natural or non-natural, as a result of design. The resilient features are instead a result of long-term development and evolution and/or randomness; efforts to try to reproduce these in a regulatory system may not be feasible (Macrory, 2014). In other words, it is doubtful whether it is at all possible to simply 'transplant' features and characteristics from, for example, an ecosystem or a marketplace into the anthropogenic system of environmental law. As highlighted in much of the literature on resilience and adaptiveness, the systems which serve as a background for the calls for a more adaptive and resilient law are highly complex and multifaceted. From this, however, it does not necessarily follow that the transplanting of specific properties deemed worthwhile from these systems into a regulatory regime will entail the desired resilience and adaptiveness. It may well be that once a feature or characteristic from one system is transplanted into another system it dispels the properties of the system from which it came and instead takes the form of the regime into which it is appropriated (Fish, 1994, p. 239). 
A perhaps more pressing problem with the attempt to deliberately design resilience features into the law relates to the epistemological limitations implicit in the emphasis on resilience. The argument for a more adaptive and resilient environmental law often rests on a two-pronged line of reasoning. The first assumption is that environmental law will face a series of unprecedented and in part unforeseen risks (foremost among which are climate change). That is, the regulatory system has little experience of the environmental risks with which the system is likely to come into contact in the future, resulting in a situation where the system itself and those charged with designing and administering the regulatory system lack full knowledge about the potential risks. The second assumption evokes what Hayek (1998) termed the 'hubris of reason', in assuming that these unpresented risks can be tackled by way of inbuilt flexibility in the regulatory system. Notwithstanding that the premise of the first assumption is that many of the risks which the regulatory system is likely to encounter will be unprecedented (i.e. it is not known what form, magnitude or extent they may have), the second assumption supposes that we can plan for and adapt to them. The argument goes: 'We do not yet know the shape, form and content of the risks we will encounter but we are nevertheless confident that a system designed with these specified properties in mind is superior in dealing with those risks.'

The inherent self-contradiction in this line of reasoning is perhaps best underlined by Marglin who argued that where 'the only certainty about the future is that the future is uncertain, if the only sure thing is that we are in for surprises, then no amount of planning, no amount of prescription can deal with the contingencies that the future will reveal' (cited in Scott, 1998, p. 344). That is, instead of using the manifestation of the unprecedented as a reminder of our 'epistemic deficit', the response of those advocating a more adaptive and resilient body of law is to argue that our epistemic deficit can be countered by instilling flexibility in the law. In some respect, this is perfectly understandable. For inherent in the call for a more adaptive and resilient regulatory system is the presupposition that the present is necessarily significantly advanced in terms of progress, knowledge and rationality, compared to any comparable point in the past. In such situations, there is, of course, nothing wrong with rejecting existing structures from past, less enlightened positions (Hirschman, 1991; Pedersen, 2015).

Recalling the point made above that many of the features often considered to represent resilience and adaptiveness are not necessarily designed with such properties in mind, it is reasonable to question whether it is at all possible to explicitly design features into the law 
which are able to 'copy' the organic resilient system. Once again Hayek's work serves as a useful reminder of the limitations associated with the attempt to construe responses to the unknown when he warns against what he saw as the 'constructivist fallacy' under which institutions will serve our 'purposes only if they have been deliberately designed for these purposes' (Hayek, 1998, p. 8). Instead it cannot be ruled out, and therefore at least consideration ought to be given to the fact that a resilient and adaptive body of law is not necessarily achieved through explicit design but through happenstance and serendipity.

In addition to the epistemological limitations encountered when seeking to explicitly design and facilitate properties of resilience in the law, there may well be reason to think that other limitations play a potential role. Thus, other factors include: legal limitations (e.g. in the form of constitutional and legislative requirements which seek to facilitate certain qualities in the law such as legal certainty and the rule of law which may well run counter to the flexibility inherent in the call for resilience and adaptiveness); and practical limitations (where resilience is facilitated by way of administrative fiat and by affording regulatory agencies discretion this may well be hampered by the often significant financial restraints under which some of the agencies find themselves). One telling example is the impact which the funding cuts to the Environment Agency's budget has had on its ability to enforce central parts of the environmental law, relating in particular to waste crime.

Notwithstanding this critique of the reasoning pursued in much of the literature on resilience and environmental law, there is nevertheless some merit in the drive towards resilience. The argument that environmental issues and risks are multifaceted and varied seems entirely reasonable and incontestable. To some extent, that is why environmental regulation looks the way it does today, representing a varied framework of, as highlighted above, different regulatory and statutory mechanisms and tools (Scotford and Robinson, 2013, p. 388). The main issue, however, relates to the rather modest appreciation of the argument that for these exact same reasons it is inherently difficult to draw up a comprehensive regulatory system which allows us to sufficiently address these risks (Pedersen, 2013b). The drive for resilience, however, is entirely understandable but the main thrust of the critique put forward here rests on the assumption that 'we must be suspicious of paradigms that pretend to give a clear-cut answer' (Hirschman, 1970, p. 339). For, as Hirschman points out: often the 'initial effort to understand reality will almost inevitably make it appear more solidly entrenched than before' (ibid.). Thus, in an attempt to response to this conundrum, it is worth considering if indeed there are other avenues through which we can in the least achieve some resemblance of 
resilience in the law. Seeing as the critique advanced above is in part anchored in the work by Hayek whose work has strong connotations of fundamental liberal democratic ideas, it is worth considering if such principles may instead serve to develop forms of resilience. One such avenue may well be that of public participation.

\section{Participation as a means towards further resilience}

One perhaps slightly overlooked factor in the resilience literature to date has been the role played by the wider public. That is, so far most of the environmental law resilience scholarship has focused on the manners in which resilience can be instilled in the legal system itself. As intimated above, there is reason to believe that system of environmental law already exhibits a certain degree of resilience. This section, however, will focus on the role played by the public in an attempt to consider whether mechanisms of public participation can be seen as successful means for allowing the public to shape specific environmental decisions which impose risk upon the public. To the extent that the public is seen as being able to shape such decisions, this may be seen as facilitating resilience. Not necessarily in the regulatory system itself but in the parts of the public subjected to particular environmental risks.

The emphasis on whether the law is able to reflect 'local' concerns and perceptions relating to particular environmental risks is important in light of the wealth of evidence indicating that for many environmental risks perceptions vary significantly between the public and 'experts', as well as between certain population groups. Thus, differences in risk perceptions by reference to sex, race and socio-economic background have been evidenced across environmental risks, indicating that women are more concerned with risk associated with hazardous waste than men (Bord and Corner, 1997); risk associated with soil pollution (Gutteling and Wiegman, 1993); and less supportive of nuclear power (Brody, 1984). Likewise, differences have been identified in perceptions of risk associated with air pollution across race (Johnson, 2002). And there is reason to believe that white males perceive environmental risks to be lower, compared to white women, black men and black women (Flynn et al. 1984; Finucane et al., 2000). In addition, research suggests that black and other non-white minorities are more concerned with risks associated with nuclear power, solid and toxic wastes, whereas white people are more concerned with 'global' risks associated with ozone depletion and climate change (Jones, 1998). In this light, it becomes relevant to consider the extent to which 
environmental law is able to strike a balance between these competing perceptions of risks and whether the law succeeds in incorporating these variations. The main prism through which to do so is the mechanism of public participation.

In general terms, public participation has played a prominent role in environmental law and governance for decades. From domestic to international environmental law, the ability of the 'public' to take part in deliberating on environmental decisions is seen as central, deferring legitimacy on outcomes. Typically this takes place through a three-pronged approach, or pillared in the Aarhus Convention terminology, emphasising access to environmental information, public participation in decision-making, and access to justice in the form of independent review mechanisms. The focus of this chapter will be primarily on the second, middle element of participation. The justifications for public involvement in environmental decision-making are several and include: that such involvement is good in its own right; the claim that participation succeeds in delivering substantively 'better' decisions (i.e. an instrumental purpose); and, linked to this, that certain members of the public are in a position to offer so-called 'situated knowledge', thereby contributing valuable and otherwise overlooked expertise to a decision (Holder and Lee, 2007; Steele, 2001). On the international level, this emphasis has enjoyed a particularly prominent position as the need to involve certain social groups, such as women, indigenous communities and the young is justified on grounds of it aiding in facilitating sustainable development. Implicit in these justifications - though perhaps not explicitly recognized - is the argument that allowing the public to take part in deliberations on the regulation of environmental risks serves to instil in those participants a certain degree of resilience; an ability to shape the regulatory responses to environmental risks and the ways in which societies adapt to these.

From the non-binding declarations of international law, obligations on public participation have over the years undergone a certain degree of firming-up to the extent that international environmental law today confers specific rights of public involvement on individuals. This is most notable in the much heralded Aarhus Convention (1998) which oblige contracting parties to facilitate public participation in a series of environmental decisions. The significance of the Aarhus Convention is perhaps best appreciated by highlighting the readiness with which other international institutions and courts have come to rely on it, as well as the way in which it has rapidly forced changes to domestic rules and practices of the contracting parties. Thus, the European Court of Human Rights has, on several occasions, come to rely on the Aarhus Convention when hearing environmental cases in the context of the Europe 
Convention on Human Rights and the Aarhus Convention has significantly shaped UK as well as EU law on the matter.

On the domestic level, public participation has been central to environmental law even before today's extensive system of regulatory controls aimed at prevention and pollution control was introduced. This is most notable from the strong emphasis on public participation found in the system of development control in the planning regime. Notwithstanding the early obligations of public participations in UK planning law have been described as 'vague [and] open-ended' and the claim that public participation took place in an environment of 'official ambivalence', statutory obligations to consult with the public are today part and parcel of the law (MacAuslan, 1980). This is principally as a result of the implementation of EU obligations flowing from, primarily, the Environmental Impact Assessment (EIA) Directive (dating back to 1985), which gives rise to more specific and tangible rights of participation for the "public concerned' where any projects fall within the directive's reach. In its current form, the EIA Directive expands public participation beyond the initial directive by noting that public participation ought not to be compromised on account of the need for a speedy decision-making process and by introducing a new obligation on the decision-maker. Upon making the decision to either refuse or permit a development, the public authority must inform the public about the ways in which the authority has responded to comments received as part of the development process and to explain how these have been incorporated or otherwise addressed (EU Directive, 2014).

The primary message to emerge from this brief overview is that, at least in principle, public participation forms an integral part of environmental law and the law thereby, seemingly, offers plenty of opportunity for affected individuals to make their representations known to public decision-makers. This is particularly so where such decisions fall within reach of the modified EIA directive. The next natural step in order to ascertain the degree to which the law succeeds in implanting resilience in individuals impacted by decisions is then to see how this works on the ground as it were. When scrutinizing how the courts have interpreted the above mentioned rules and regulations, and the way these are applied in practice, there is, however, cause for concern. The subsequent part of the chapter examiners these matters in turn.

\section{Participation in practice}


If, in the attempt to ascertain the extent to which the above discussed rules on public participation are interpreted and implemented in practice, one turns to the manner in which the courts have dealt with public participation in practice, one encounters an increasingly mixed picture of highs and lows. In the context of EIA, the initial approach taken by the UK courts in the early cases was famously one of reticence. Thus in $R$ v. Swale Borough Council, ex parte $R S P B$, in which the RSBP sought to challenge the decision not to conduct an EIA as part of a planning application for a storage area in connection with a port facility, and thereby also the failure to carry out a consultation, Simon Brown Justice (as he then was) famously held that the decision as to whether a development fell within the reach of the EIA Regulations on account of having a 'significant' environmental impact was entirely a matter for the planning authority's discretion. This overly deferential approach has not, however, entirely withstood the test of time and in its landmark decision in Berkeley v. Secretary of State for the Environment, the House of Lords famously took steps to underline the importance of the EIA regime and its emphasis on public involvement in environmental decision-making. In a very purposive-driven decision, Lord Hoffmann thus highlighted how:

The directly enforceable right of the citizen which is accorded by the Directive is not merely a right to a fully informed decision on the substantive issue. It must have been adopted on an appropriate basis and that requires the inclusive and democratic procedure prescribed by the Directive in which the public, however misguided or wrongheaded its views may be, is given an opportunity to express its opinion on the environmental issues (Berkeley, 38 per Lord Hoffmann)

Not surprisingly, Berkeley has been highlighted as the high-water mark in the courts' approach to and development of public participation in the UK (alongside the decision of the High Court in $R$ (on the application of Greenpeace) v. Secretary of State for Trade and Industry, which famously held that the government's consultation on nuclear energy was fatally flawed). More recently, however, the courts have seemingly reverted to a less purposive stance and fallen back on the assumption that the courts retain ultimate discretion when it comes to providing remedies (i.e. to quash) where decisions have been made in contravention of underlying EU rules on public participation.

In Walton v. Scottish Ministers, the Supreme Court, in response to a statutory appeal against the approval by the Scottish Government of certain specific routes within an extensive 
road construction network, thus signalled a slight shift away from Berkeley by suggesting that the Court will not as a matter of course quash a decision taken in violation of underlying EU rules. Instead, Lord Carnwath suggested that the real issue is somewhat more pragmatically whether the applicant will have suffered 'substantial prejudice', i.e. whether the applicant in case 'has been able in practice to enjoy the rights conferred by the European legislation' on public participation (Walton v. Scottish Ministers, 139). The argument that an illegality does not necessarily result in the underlying decision being quashed was further supported by the Supreme Court in $R$ (Champion) v. North Norfolk District Council, again relating to the failure to comply with the EIA Directive. Once again stressing the fact that notwithstanding the lack of compliance with the relevant EIA procedures (and thereby the formal public participation requirements) the Court found that the public had been fully involved in the decision-making process and that the contested decision would therefore not have been different had the EIA procedures been followed ( $R$ (Champion) v. North Norfolk District Council, pp. 58-60). That is, substantive though not formal compliance had, in the view of Lord Carnwath, in reality taken place.

In light of this change of, at the least rhetoric, one conclusion to draw is that the UK courts are presently less inclined to afford full protection to the importance of public participation in environmental decision-making. This move does not perhaps bode well for the present analysis and its emphasis on public participation as a means with which to facilitate resilience if in reality individuals affected by environmental risks are not able to enforce the underlying rules of public participation. This is particularly problematic where public participation and involvement of individuals may have the potential to serve as a correction to the problems identified above with the primarily technocratic developments of the law. If this is correct, then the approach taken by the courts leaves a lot to be desired from the point of view of resilience. Perhaps an altogether more reasonable reading would, however, suggest that the courts are simply seeking to strike out a more pragmatic line, attempting to balance the competing pressures of the desire of the public for further participation, and the impact this has on the delay and costs of the decision-making. And naturally, the various cases will have to be appreciated in their specific and concrete contexts. Thus, in Berkeley, as Lord Carnwath pointed out in Walton, the House of Lords was aided by the fact that by time the dispute came before their Lordships, the developer had withdrawn the proposal and abandoned the project. The strong purposive statements made in Berkeley were therefore, while not empty gestures, perhaps somewhat low cost in the context of the specific case (see also $R$ (Edwards) v. 
Environment Agency). Moreover, in Walton, the applicant had indeed enjoyed the right to participation at several stages throughout the decision-making process and had had ample opportunity to make his representations to the decision-maker (Lord Carnwath, while not under a legal obligation to do so, took inspiration from the fact that the Compliance Committee of the Aarhus Convention had previously found that the applicant had had several opportunities to make representations throughout the decision-making process). Nevertheless this apparent retreat in the case law on public participation potentially serves to limit the usefulness of public participation as a mechanism through which to impress strands and ideas of resilience upon the environmental decision-making process. Additional support for this is arguably found in some of the empirical work examining the ways in which public participation is conducted on the ground.

Thus work on public participation in decisions relating to major wind energy projects highlights how, in reality, public participation provisions have little impact on high level policy decisions (Lee et al., 2012). The work by Lee et al. suggests that in situations where a policy commitment has been made to a particular course of action, there is often little scope for the public to influence subsequent specific decisions, notwithstanding the statutory entitlement to do so. Tellingly, Lee et al. (2012, p. 59) warn against what they see as a 'hollowness in participatory exercises at the consenting stage for major projects'. Moreover recent work suggests that where official policy and guidance create a presumption in favour of certain decisions and developments, decision-makers seemingly afford more weight to representations and knowledge offered by experts as opposed to concerns raised by members of the public (Rydin et al., 2015). This is likely to surprise few, and it may well be that the public and others expect too much from the public participation mechanisms but in light of the argument made above that public participation provision may have the potential to serve as a corrective influence and thereby indirectly facilitate resilience in a decision-making, this is indeed a shame highlighting that 'frustrations, misunderstandings, and failures is located at more fundamental levels: in conflicting values, expectations, and attitudes about participation, and in the limited incorporation of results in the wider policy-making process' (Wesselink et al., 2011, p. 2689).

\section{Conclusion}


This chapter has sought to examine the relationship between the concept of resilience and environmental law in the UK. The main claim to emerge from this investigation is that many of the features which are ordinarily associated with resilience are in fact already found in the law, albeit to varying degrees. Importantly, these features have often made their way into the law by way of happenstance and serendipity. An upshot of this, however, is that some of these features may inherently result in existing inequalities being amplified. This is most notable in the part of the law which, through flexible mechanism of technocratic participation, runs the risk of exacerbating existing structures of inequality and lack of involvement of certain social groups; often the ones most likely to face certain environmental risks at the end of a regulatory process (e.g. in the form of close contact with industrial processes). There is little to suggest that traditional methods and means of public participation are able to counter this. This is important for several reasons for those seeking to develop resilient features in regulatory systems wherever this may be. Foremost is the fact that lack of knowledge of the actual environmental risks significantly limits the ability of a regulatory system to respond to risks. In response to this, the chapter has thus sought to challenge the claim that the characteristics which are most commonly associated with facilitating resilience in a system are capable of being replicated and created in a regulatory system like that of environmental law. Thus the chapter has highlighted how the attempt to develop and facilitate resilience in the regulatory system of environmental law runs into considerable problems when the premises of this attempt are scrutinized in detail. The analysis proffered in this chapter of the experience from the UK consequently suggests that the creation of a resilient environmental law system is a slow, incremental (and naturally frustrating) endeavour.

\section{Bibliography}

Abbot, Caroline and Maria Lee (2015) 'Economic Actors in EU Environmental Law' 34 Yearbook of European Law 26-59

Arnold, Craig Anthony and Gunderson, Lance H (2014) 'Adaptive law and Resilience' Legal Studies Research Paper Series Paper No. 2014-04 
Benson, Melinda Harm (2015) 'Reconceptualising Environmental Challenges - Is Resilience the New Narrative?' 21 J. Envtl. \& Sustainability L 99

Bord, Richard J and O'Connor, Robert E (1997) 'The Gender Gap in Environmental Attitudes: The Case of Perceived Vulnerability to Risk' 78 Soc Sci Q 830

Brody, Charles J (1984) 'Differences by Sex in Support for Nuclear Power' 63 Social Forces 209

Craig, Robin Kundis (2016) 'Learning to Live with the Trickster: Narrating Climate Change and the Value of Resilience Thinking' Pace Environmental Law Review forthcoming

Finucane, M.L., Slovic, P., Mertz, C.K., Flynn, J. and Satterfield, T.A. (2000) 'Gender, Race, and Perceived Risk; The "White Male Effect"' Health, Risk \& Society, 2 (2): 159-72.

Fish, Stanley (1994) 'Being Interdisciplinary is so Very Hard to Do' in in S Fish, There is no Such Thing as Free Speech: And it's a Good Thing Too (OUP)

Fisher, Elizabeth, Lange, Bettina and Scotford, Eloise (2013) Environmental Law Text, Cases and Materials (Oxford University Press)

Flynn, James, Slovic, Paul and Mertz, CK (1984) 'Gender, Race, and Perception of Environmental Health Risks' 14 Risk Analysis 1101

Gutteling, Jan M and Wiegman, Oene (1993) 'Gender-Specific Reactions to Environmental Hazards in the Netherlands' 28 Sex Roles 433

Hawkins, Keith (1984) Environment and Enforcement: Regulation and Social Definition of Pollution (Oxford University Press)

Hayek, FA (1998) Law, Legislation and Liberty (Oxford, Routledge)

Hirschman, Albert O (1970) 'The Search for Paradigms as a Hindrance to Understanding' 22 World Politics 329-343

Hirschman, Albert O (1999) The Rhetoric of Reaction (Harvard University Press) 
Holder, Jane and Lee, Maria (2007) Enmvironmental Law (Cambridge University Press)

Holling, CS (1973) 'Resilience and Stability of Ecological Systems' 4 Ecological Systems 123

Johnson, Branden B (2002) 'Gender and Race in Beliefs about Outdoor Pollution' 22 Risk Analysis 725

Jones, Robert E (1998) 'Black Concern for the Environment: Myth versus Reality' 11 Society and Natural Resources 209

Kim, Rakhyn E and Bosselman, Klaus (2013) 'International Environmental Law in the Anthropocene: Towards a Purposive System of Multilateral Environmental Agreements' 2 Transnational Environmental Law 285-309

Lange, Bettina (2008) Implementing EU Pollution Control (CUP)

Lee, M., Armeni, C., de Cendra, J., Chaytor, S., Lock, S., Maslin, M., Redgwell, C. and Rydin, Y. (2012) 'Public participation and climate change infrastructure', Journal of Environmental Law, 25(1): 33-62.

MacAuslan, Patrick (1980) The Ideologies of Planning Law (Oxford, Pergamon Press)

Macrory, Richard (2014) Regulation, Enforcement and Governance in Environmental Law (Oxford, Hart)

McDonald, Jan and Styles, Megan C (2014) 'Legal Strategies for Adaptive Management under Climate Change' 26 JEL 26-53

Pedersen, Ole W (2013a) 'Environmental Enforcement Undertakings and Possible Implications: Response, Smarter or Rent Seeking?' 76 MLR 319-345

Pedersen, Ole W (2013b) 'Modest Pragmatic Lessons for a Diverse and Incoherent Environmental Law' 33 OJLS 103-131 
Pedersen, Ole W (2015) 'The Rhetoric of Environmental Reasoning and Responses as Applied to Fracking' 27 JEL 325-334

Ruhl, JB (1997) 'Thinking of Environmental Law as a Complex Adaptive System: How to Clean up the Environment by Making a Mess of Environmental Law' 34 Hous. L. Rev. 933.

Ruhl, JB (2011) 'General Design Principles for Resilience and Adaptive Capacity in Legal Systems - With Application to Climate Change Adaptation' 89 N.C. L. Rev. 1373

Rutter, Michael (2012) 'Resilience as a Dynamic Concept' 24 Development and Psychopathology 335-344

Rydin, Yvone, Lee, Maria and Lock, Simon J (2015) 'Public Engagement in Decision-Making on Major Wind Energy Projects' 27 JEL 139-150

Scott, James C (1998) Seeing Like a State (New Haven, Yale University Press)

Scotford, Eloise and Robinson, Jonathan (2013) 'UK Environmental Legislation and Its Administration in 2013 - Achievements, Challenges and Prospects' 25 JEL 383-409

Steele, Jenny (2001) 'Participation and Deliberation in Environmental Law: Exploring a Problem-Solving Approach' 21 OJLS 415-442

Tamanaha, Brian (2001) A General Jurisprudence of Law and Society (OUP)

Wesselink, A., Paavola, J., Fritsch, O. and Renn, O. (2011) 'Rationales for public participation in environmental policy and governance: practitioners' perspectives'. Environment and Planning A 43(11): 2688-704.

\section{Cases}

$R$ v. Swale Borough Council, ex parte RSPB [1991] 1 PLR 6

Berkeley v. Secretary of State for the Environment [2001] Env. L.R. 16 
$R$ (on the application of Greenpeace Ltd) v. Secretary of State for Trade and Industry [2007] EWHC 311

$R$ (Edwards) v. Environment Agency [2008] UKHL 22.

Walton v. Scottish Ministers (Scotland) [2012] UKSC 44

$R$ (on the application of ClientEarth) (Appellant) v. Secretary of State for the Environment, Food and Rural Affairs (Respondent) [2015] UKSC 28 and [2013] UKSC 23.

$R$ (on the application of Champion) v. North Norfolk District Council and another [2015] UKSC 52.

\section{Legislation}

Climate Change Act 2008.

Environmental Permitting (England and Wales) (Amendment) (England) Regulations 2015.

EU Directive 2014/52/EU of the European Parliament and of the Council of 16 April 2014 amending Directive 2011/92/EU on the assessment of the effects of certain public and private projects on the environment.

EU Industrial Emissions Directive 2010 Directive 2010/75/EU of the European Parliament and of the Council of 24 November 2010 on industrial emissions (integrated pollution prevention and control). 